\title{
Thermal comfort and its relation to ventilation approaches in non-air-conditioned mosque buildings
}

This paper reports the outcome of a thermal comfort study that assessed the satisfaction of occupants with their surrounding thermal conditions. The study was carried out in 10 mosque buildings around lowland Nibong Tebal, Penang and highland Cameron Highlands, Pahang. It involved determining the compliance level of thermal comfort parameters (i.e. air temperature, relative humidity and air speed) at lowland and highland and establishing relationships between ventilation systems with predicted mean vote and predicted percentage of dissatisfied at lowland and highland according to ASHRAE Standard-55. The study was conducted from $1200 \mathrm{~h}$ to $1700 \mathrm{~h} / 1730 \mathrm{~h}$ to assess the thermal conditions of the 10 mosques during Zohor/Friday and Asar prayer times. During prayer times, an active ventilation system was in operation, while before and after prayer times, only passive ventilation (windows and doors) was available. Overall, findings indicated that better thermal comfort conditions occurred during prayer time at highland compared with those at the lowland, with the thermal sensation conditions of mosques in the former 'slightly warmer' to 'slightly cool' and in the latter 'slightly warm' to 'hot'. Moreover, most mosques at lowland did not provide good thermal comfort because the percentage of dissatisfied was high compared to that at highland.

Keyword: Mosque; PMV; PPD; Thermal comfort; Ventilation 